\title{
(息)
}

Citation:

Carrington, B (2015) Assessing the sociology of sport: On race and diaspora. International Review for the Sociology of Sport, 50 (4-5). 391 - 396. ISSN 1012-6902 DOI: https://doi.org/10.1177/1012690214559857

Link to Leeds Beckett Repository record:

https://eprints.leedsbeckett.ac.uk/id/eprint/1588/

Document Version:

Article (Updated Version)

The aim of the Leeds Beckett Repository is to provide open access to our research, as required by funder policies and permitted by publishers and copyright law.

The Leeds Beckett repository holds a wide range of publications, each of which has been checked for copyright and the relevant embargo period has been applied by the Research Services team.

We operate on a standard take-down policy. If you are the author or publisher of an output and you would like it removed from the repository, please contact us and we will investigate on a case-by-case basis.

Each thesis in the repository has been cleared where necessary by the author for third party copyright. If you would like a thesis to be removed from the repository or believe there is an issue with copyright, please contact us on openaccess@leedsbeckett.ac.uk and we will investigate on a case-by-case basis. 


\section{Assessing the Sociology of Sport: On Race and Diaspora}

\section{Reflections on the Trajectory of the Sociology of Sport}

Does "the sociology of sport" exist? It may seem perverse, perhaps even disrespectful, to ask such a question as we celebrate the 50th anniversary of the International Sociology of Sport Association and this august journal, but I think, at such a moment, it is worth reflecting upon what precisely the "it" is of sport sociology. When talking about the emergence of sport sociology as a discrete area of study, we tend to mention its founding figures, seminal texts, certain groundbreaking conferences, its leading Anglophone journals (like IRSS) and particular centers of work, usually located within western universities, as formations that constitute the object. This is clearly one way to think about "the sociology of sport" as a singular entity. There is a (self-produced) discourse that claims that a sociology of sport exists, we point to labels that have this name, and from there we measure whether "it" is expanding or contracting, becoming more vibrant or declining in significance. But the prior question of its facticity is ignored or, more often, simply assumed.

As we take stock of the past half-century, I want to suggest that the sociology of sport has never been more impactful than it is right now and perhaps also at its weakest institutional moment. This poses a conundrum: was the emergence of the sociology of sport a way to get "mainstream sociology" to take sport seriously (in which case it has been a spectacular failure) 
or a move to develop a separate, if aligned, area of study that would, over time, become a selfsustaining entity (in which case there may be some cause for celebration). Further, whilst sport sociology can claim some success in deepening the public discourse when it comes to thinking about the complex social relations produced by sport, whether sport sociology gets the credit for this is unclear. Put another way, sport sociology's success in creating a space distinct from leisure studies, human movement studies, physical education, and the study of popular culture, has paradoxically given the field an internal vibrancy whilst increasing its marginalization.

\section{Assessing the Challenges of the Sociology of Sport}

The sociology of sport is a curious object. The sociological study of sport rarely takes place within sociology. Over the past 50 years only 24 articles on sport have been published in the three main US sociology journals, or about two sports-related articles per decade in each journal. None has had a special issue devoted to sport (Carrington 2013). Interestingly, British sociology is relatively better, with 69 articles focused primarily on sport published in the top three journals since 1963 (Carrington 2013). In setting out to demonstrate to the parent discipline the undeniable importance of sport, in seeking to show how sports matter, a curious bifurcation has emerged wherein the mainstream institutions of the discipline all but ignore sport as meaningful subject matter, whilst sport studies scholars have busily established their own self-reproducing spaces of critical enquiry. We might suggest that the "subdiscipline" has become marginalized due to its very success. It's not surprising then that approximately $70 \%$ of authors publishing in the main sociology of sport journals do not actually work in departments of sociology but primarily in departments of kinesiology, sports studies and physical education 
(Carrington 2013). Put bluntly, and with some rare exceptions, sociology departments do not hire people who work on sport (as they do in other subdiscplinary areas such as health, education, migration and so on) and most of the "big names" of sports sociology tend to work in interdisciplinary sports studies departments where the dominant focus is often on improving the performance of elite athletes, teaching sports management techniques, or on physical education training. Lacking the "protection" of the parent discipline of sociology (because it was never really in that house anyway), and facing shrinking cohorts of undergraduate "consumers" wanting and willing to be exposed to alternative ways of understanding sport and physical culture beyond learning how to make bodies run faster or discipline them into being more healthy and active citizens, the institutional outlook appears fantastically fragile. In the neoliberal age of austerity and instrumental learning, trying to convince undergrads (let alone Deans) to understanding the relevance of Antonio Gramsci to the sports they love seems nostalgically utopian.

The paradox is that the current institutional crisis for the sociology of sport is occurring at precisely the moment when the insights produced over the past fifty or so years have never been more needed or more extensively used. Changing attitudes towards sexuality and the expansion of gay, lesbian and transgender rights is nowhere highlighted more powerfully than in contemporary sports. The very legitimacy of mega-sporting events has been so thoroughly questioned that organizations like FIFA and the IOC are, arguably, and for the first time, having to defend their practices and policies. The rights of athletes to protest and organize, from so- 
called student-athletes in US college sports to international cricket players showing solidarity for the Palestinian freedom struggle, are as likely to dominate sports media commentary as the latest scores and transfer news. All of these discussions are informed by the research and thinking of sports sociologists, work that is increasingly used by journalists such as Rob Steen in the UK and Dave Zirin in the US. The humanist desire to study sport in order to understand its hidden meanings as a way to make sports "better" - and as a result enrich our lives - is now being achieved to a far greater extent than ever before, even as sport sociology's pivotal and central role is often overlooked. Thus non-sport sociologists, most of whom have never participated in the formal academic spaces of sport sociology, such as Elizabeth Wilson and her widely reviewed history of tennis or the varied football writings of David Goldblatt, have garnered national and international public attention for their work which is based upon decades of sport sociology research. Websites such as deadspin.com and bleacherreport.com contain informed and critical appraisals of the sports-society nexus that is profoundly sociological, even if they do no claim to be sports sociologists.

Does any of this matter? Cultural studies, for example, has transformed the ways in which we understand culture, power, ideology and identity but it never had a strong institutional basis within the academy. The sociology of sport perhaps faces a somewhat similar predicament. Its ideas have saturated the wider zeitgeist, its critical insights help to shape public discussions over sport's possibilities and limits, yet its formal recognition as a legitimate area of enquiry seems to dissipate by the semester. The speed with which sport sociology currently finds itself 
fighting to maintain a foothold within academia, at least within the UK and the US, suggests that it was never as embedded, never as coherent, as we believed it to be. Outside the discourse of sport sociology, does it actually exist? Sociologically informed approaches to understanding the significance of sport will no doubt continue but whether this will occur under the banner of "The Sociology of Sport" remains less clear.

\section{Future Directions for the Sociology of Sport: On Race and Diaspora}

"Diaspora" is one of the most important concepts in contemporary social theory and a burgeoning area of study yet it is frequently and surprisingly ignored within sport studies and the sociology of sport (Carrington 2010). Given that sport sociology often likes to think of itself as on the cutting edge of new debates and modes of enquiry, this absence is striking. Key sport theorists have largely failed to engage the expansive literature on diaspora as a way to consider sporting identifications, flows and possesses that exceed nation state frameworks, relying instead on traditional approaches found within globalization theory. For example, in Joe Maguire's (1999) Global Sport diaspora isn't discussed at all - see as well Maguire's (2005) Power and Global Sport - while Alan Bairner's (2001) Sport, Nationalism and Globalization contains a few descriptive comments, mainly restricted to referencing the Irish diaspora. Ellis Cashmore's (2000) Sports Culture: An A-Z Guide, Stephen Wagg et al.'s (2009) Key Concepts in Sports Studies, Dominic Malcolm's (2008) The Sage Dictionary of Sports Studies, and Alan Tomlinson's (2010) Oxford Dictionary of Sports Studies, all contain entries for globalization but none of these definitive reference texts discuss diaspora. Even in Richard Giluianotti's (2011) otherwise comprehensive anthology, Sociology of Sport, which contains 78 chapters across four 
volumes, there is not a single chapter specifically on diaspora. Miller et al.'s (2001) Globalization and Sport, is perhaps an exception here as the text does at least recognize the importance of the concept and includes it in the glossary of key terms. To say, then, that diaspora has been overlooked as a concept within sport sociology is something of an understatement.

Thinking about race through the conceptual lens of diaspora has enabled critical race scholars to problematize the often Eurocentric and teleogical underpinnings of globalization theory. It provides a framework to think about social movements, relations and politics in a way that does not automatically defer to the nation state as either the primary or only unit of analysis. Notions of place and identity have also been rethought, less in terms of fixity and rootedness but instead through notions of flow and routes. Similarly, migration becomes less a one-way movement resulting in the loss of a home identity and assimilation into the new, than about the continual (re)negotiation of identities, understood as hybrid and contingent through a process of contestation that ultimately reshapes the imaginary both the "sending" and "host" countries. Mapping the dispersal of peoples (forced, coerced and voluntary), the ways in which collective memory and consciousness of displacement are produced and maintained across geography and through history, as well as understanding the vexed political questions of exile, return and belonging, have proved fruitful for many contemporary scholars. Key here would include Paul Gilroy's (1993) rethinking the relationship between culture, slavery, and modernity, Avtar 
Brah's (1996) theorizing on the politics of intersectionality and the geographical registers of race, and James Clifford's (2007) work on travelling cultures, movement and identity.

Sport has tended to be overlooked within this literature, but a new generation of scholars have begun to use the concept of diaspora as an interpretive frame to produce more complex accounts of how sport connects geographical dispersed groups whilst helping to create new (sometimes resistant) identities and differentiated subjectivities in often hostile circumstances. For much of this work, Europe's colonial encounters, and the anti-colonial struggles produced as a result, form the starting point for enquiry (rather than the de-racialized economic frameworks favored by globalization theorists). Daniel Burdsey's work on British South Asian communities, Janelle Joseph's ethnographies on black Caribbean cricketers in Canada, Theresa Runstedler's historical research on the travels and travails of African American athletes, and Mette Andersson's studies on black diasporic identifications in Norway, are examples of recent work that is creatively reshaping the race and sport research agenda. This work offers a model for the rest of sport sociology beyond its fixation with analyzing professional men's elite sports and static nation-state frameworks. The turn to diaspora does not "solve" the questions posed by earlier generations of scholars but it does present us with new problematics that require a reorienting of our methodologies and approaches beyond the restrictive frameworks of nationstate sociology. 


\section{References}

Bairner, A. (2001) Sport, Nationalism, and Globalization: European and North American perspectives, Albany: State University of New York Press.

Brah, A. (1996) Cartographies of Diaspora: Contesting identities, London: Routledge.

Carrington, B. (2010) Race, Sport and Politics: The sporting black diaspora, London: Sage.

Carrington, B. (2013) "The Critical Sociology of Race and Sport: The first fifty years", in Annual Review of Sociology, 39, pp. 379-398.

Cashmore, E. (2000) Sports Culture: An A-Z Guide, London: Routledge.

Malcolm, D. (2008) The Sage Dictionary of Sports Studies, London: Sage.

Tomlinson, A. (2010) Oxford Dictionary of Sports Studies, Oxford: Oxford University Press.

Giluianotti, R. (2011) Sociology of Sport, Volumes 1-4, Sage: London.

Clifford, J. (1997) Routes: Travel and Translation in the Late Twentieth Century, Harvard University Press: Cambridge.

Gilroy, P. (1993) The Black Atlantic: Modernity and double consciousness, London: Verso.

Maguire, J. (1999) Global Sport: Identities, societies, civilizations, Cambridge: Polity Press.

Maguire, J. (2005) Power and Global Sport: Zones of prestige, emulation and resistance, London: Routledge.

Miller, T., Lawrence, G., McKay, J. and Rowe, D. (2001) Globalization and Sport: Playing the world, London: Sage.

Wagg, S., Wheaton, B., Brick, C, and Caudwell, J. (2009) Key Concepts in Sports Studies, London: Sage. 